\title{
0 ensaio sobre o dom de Marcel Mauss: um texto pioneiro da crítica decolonial
}

PAULO HENRIQUE MARTINS"

Resumo

O objetivo deste artigo é mostrar que Marcel Mauss, em seu Ensaio sobre o dom, publicado em 1924, desenvolve uma reflexão pós-colonial avant la lettre que estrutura toda a sua crítica antiutilitarista do ocidentalismo e que pode esclarecer uma série de aspectos da crítica decolonial, especialmente em suas relações atuais com o pensamento antiutilitarista desenvolvido na Europa.

Palavras-chave: Mauss. Pós-colonialidade. Crítica decolonial.

Marcel Mauss' The Gift: a pioneering work of the decolonial critique

\section{Abstract}

The purpose of this article is to demonstrate that Marcel Mauss, in his Essai sur le Don (The Gift), published in 1924, elaborates a sort of avant la lettre postcolonial thinking that structures his whole anti-utilitarian criticism of the Occidentalism and that may clarify some aspects of the decolonial criticism, particularly in its current relations with anti-utilitarian thinking developed in Europe.

Keywords: Mauss. Postcolonialism. Decolonial criticism.

\footnotetext{
* Universidade Federal de Pernambuco. Recife (Brasil)
} 


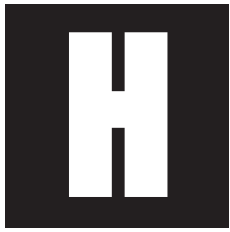

á em Mauss um pensamento pós-colonial ${ }^{1}$ que avança em direção a uma crítica decolonial ${ }^{2}$, isto é, que propõe a revalorização de saberes esquecidos ou negligenciados. Nessa perspectiva, Mauss, ao longo de toda a primeira parte do Ensaio, faz um esforço intelectual considerável para descrever rituais históricos, culturais e simbólicos nãoeuropeus como o potlatch ${ }^{3}$, o que, no nosso ponto de vista o coloca como um pioneiro deste pensamento. O diferencial de Mauss foi dar legitimida-

\footnotetext{
${ }^{1}$ Há uma distinção entre as formas de pensamento pós-colonial e aquela a que nos referimos como decolonial. O termo pós-colonial se refere à reflexão intelectual que acompanha o processo colonial. Nesse tipo de reflexão, levanta-se em geral a questão das relações entre centro e periferia - que foi o elemento-chave da crítica anti-imperialista - sem romper, no entanto, com o dogma do crescimento econômico, que é central nas teorias que tratam do tema da modernização (Wallerstein, 2006). Teorias como o estruturalismo ou a teoria da dependência representaram inovações pós-coloniais. O que chamamos de pensamento decolonial rompe com esta ideologia ao relativizar a ideia de ciência universal. As teses decoloniais decorrem da emergência de novos paradigmas em ciências sociais na Europa, partindo do estruturalismo rumo a outros caminhos, sobretudo na década de 1980. O pensamento decolonial é, assim, tributário das filosofias de Michel Foucault e Jacques Derrida. Continuando, em parte, pós-coloniais, essas novas ideias são também antiutilitaristas, no sentido de que pretendem atualizar os conhecimentos e práticas que haviam sido reprimidos pelo racionalismo científico ocidental (Martins, 2010).

${ }^{2} \mathrm{O}$ termo decolonial não é unânime. Por exemplo, Dipesh Chakrabarty et al (2007, p. 3) o consideram ambíguo, porque exigiria, segundo eles, uma libertação completa do colonialismo. Eles preferem falar de hybridizing encounter. Alain Caillé observa que muitas dessas críticas são negativas, sem fornecer oportunidades para a reconciliação (Caillé, 2010, p. 51). De nossa parte, acreditamos que essas críticas são legítimas. O desafio central não é romper com a sociologia moderna, mas libertar o que foi reprimido pela colonização. Parece justo dizer que o pensamento decolonial é a tarefa de desconstrução do poder e do conhecimento, seguido da reconstrução e/ou do surgimento de outras formas de poder e conhecimento.

${ }^{3}$ Potlatch é um festejo religioso de tribos indígenas dos Estados Unidos da América e do Canadá, muito comum no século XIX, e que é descrito por Mauss no Ensaio sobre a dádiva. Este ritual sobreviveu no século XX, apesar das reações das autoridades governamentais daqueles países, que o consideravam "irracional". A palavra potlatch significa dar, caracterizando o ritual como de oferta de bens e de redistribuição da riqueza. O potlatch se constitui de homenagem com presentes variados como dinheiro, taças, copos, mantas, entre outros, que era comum entre as tribos. Diz Mauss que essas tribos acumulavam bens, em uma época do ano, para poder realizar as doações na estação seguinte. $\mathrm{O}$ valor e a qualidade dos bens dados como presente são sinais do prestígio do homenageado e quanto maior a doação, maior o reconhecimento. No limite, a doação poderia significar o sacrifício da própria vida do doador.
} 
de a esses outros saberes, bebendo da fonte de culturas estrangeiras para realizar uma crítica moral e estética do utilitarismo econômico europeu. Não estaríamos tentados a dizer, então, que o charme do dom vem justamente de sua origem não europeia e que, de fato, esta teoria bebe da fonte de culturas estrangeiras para realizar uma crítica moral e estética do utilitarismo econômico europeu?

Outro aspecto a reforçar nossa hipótese é a aproximação inesperada que podemos estabelecer entre a abordagem de Mauss e a tese do historiador indiano Dipesh Chakrabarty (2008), da Universidade de Chicago - uma das teses mais interessantes, entre os estudos pós-coloniais, sobre a "provincialização da Europa". De acordo com Chakrabarty, a hegemonia do universalismo liberal tem obscurecido o fato de que o racionalismo e a ciência não são apenas traços europeus particulares, mas também o resultado de uma história "global" que implica todas as sociedades coloniais na epopeia europeia da modernização. Essa hegemonia da Europa, diz ele, ajudou a espalhar uma imagem invertida, na qual o conhecimento europeu é universal e os "outros" são conhecimentos particulares.

Retornando ao autor do Ensaio, pode-se então argumentar que, na tentativa de organizar um paradigma crítico do ocidentalismo, inspirado nas culturas não europeias - o dom, através do ciclo de dar-receber-retornar -, Mauss ajuda a desconstruir o universalismo europeu, ou, como diria Chakrabarty, ele "provincializa" a Europa. Esse tipo de abordagem mostra que a crítica pós-colonial ou decolonial não se limita apenas a reivindicações identitárias de intelectuais nascidos nas ex-colônias. A colonialidade do saber é um processo mais amplo de dominação patriarcal, obtido através da colonização do planeta e, ao mesmo tempo, na Europa, através da submissão das populações às hierarquias coloniais de gênero, etnia, trabalho, cultura, religião entre outros. Por essa razão, hoje, já se delineiam entre os autores europeus ${ }^{4}$ que lançam um olhar

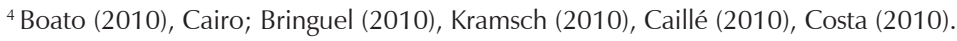


sobre a descolonização da Europa e suas hierarquias de dominância baseadas em elementos não-econômicos, linhas de pesquisa voltadas a desconstruir o eurocentrismo.

Isto é de grande importância para a crítica geral do capitalismo. De fato, a colonialidade do poder ${ }^{5}$ e a organização do capitalismo de mercado caminham lado a lado. A criação dos Estados Nacionais contribuiu para estabelecer um vínculo entre o Estado e o mercado, o que foi necessário para submeter as populações que vivem no território das sociedades modernas (na Europa ou em outros lugares) a uma classificação de ordem binária útil à biopolítica moderna (Foucault, 2004). Foi esta operação de distinção entre cidadãos brancos e cidadãos negros, nativos e imigrantes, homens "racionais" e mulheres "emocionais" que permitiu organizar a dominação simultânea das oligarquias econômicas e dos colonizadores, dentro e fora da Europa. Em outras palavras, a biopolítica, segundo os princípios enunciados por Foucault, tem sido uma condição necessária para a organização da colonização do poder e as relações entre o patriarcado, o capitalismo e o cristianismo, independentemente das sociedades do centro ou da periferia. Isto significa que a desconstrução do eurocentrismo requer uma crítica ao mesmo tempo decolonial e antiutilitarista.

Essa é a tese que procuramos aprofundar nas páginas seguintes, tendo em vista que Mauss, em seu Ensaio, percebeu muito cedo o desafio de uma discussão sobre a relação entre crítica decolonial e crítica antiutilitarista. Nessa linha de reflexão, gostaríamos de assinalar, nesta rápida apresentação, que a originalidade do presente texto se verifica no esforço

\footnotetext{
${ }^{5}$ Colonialidade do poder é um conceito elaborado pelo sociólogo peruano, A. Quijano, para definir a constituição do capitalismo colonial moderno como um padrão de poder mundial que se apoiou sobretudo na ideia de raça (raza) para objetivar uma estratégia de classificação social da população mundial. A ideia de raça permitiu a distinção moral e política entre os "brancos" e os "não-brancos" (Quijano, 2003).
} 
de redirecionar o olhar do leitor à tensão contida no Ensaio entre o elogio - implícito - a saberes não europeus e a crítica - explícita - do utilitarismo econômico eurocêntrico.

\section{Do pensamento classificatório cognitivista ao pensamento simbólico}

A articulação entre o pensamento antiutilitarista e o pensamento decolonial demonstra sua atualidade quando constatamos que a crítica à filosofia mercantilista, desenvolvida por sociólogos durante os dois últimos séculos, se revela hoje insuficiente para conter a onda expansiva do neoliberalismo, como já o explicou diversas vezes Alain Caillé (2000; 2009). Nesse sentido, a reação das ciências sociais contra as ameaças inquietantes de um pensamento único utilitarista também se baseia na reconsideração de temas não-econômicos que se expressam nos aspectos políticos, militares e ideológicos da colonização planetária. A problemática do "espírito colonial" ajuda a demonstrar que o capitalismo é uma produção histórica e cultural determinada, assim como o fez, em seu tempo, Karl Polanyi, em A Grande Transformação; como também o fez, Marcel Mauss, no Ensaio, revelando que a sociedade é composta de uma série de prestações totais envolvendo o conjunto das instituições sociais, sejam elas jurídicas, econômicas, religiosas ou estéticas (Mauss, 1999, p. 274).

O estudo dessas obras hoje clássicas nos leva a reconhecer a importância, para a crítica teórica, das práticas e experiências nascidas em sociedades não europeias, algumas provenientes de tradições milenares. Em particular, reconhecer a importância da obra de Mauss para a crítica decolonial leva necessariamente a pensar a relação entre o capitalismo e a colonização, tendo em conta dois aspectos do processo de colonização: o de dentro, o eurocentrismo, e o de fora, aquele das margens 
da Europa ou do que se chamava "Terceiro Mundo". Isto significa que a descrição da modernização deve ser realizada a partir da perspectiva europeia, mas também a partir do exterior, das bordas, ou seja, tanto a partir do olhar dos países "centrais" como daquele das "periferias" ${ }^{6}$. A crítica antiutilitarista se enriquece com a crítica decolonial, pois entendemos que esta última também procura incorporar, na análise sociológica, os diversos fenômenos culturais, tradicionais, religiosos, políticos, linguísticos e rituais ${ }^{7}$. Demonstramos, aliás [Martins, 2010; 2011], que a crítica pós-colonial é um processo abrangente o qual muda nossa visão da colonização simultaneamente a partir do Sul e do Norte, a partir de "dentro" e de "fora" do processo colonizador ${ }^{8}$.

Em nossa opinião, a abordagem relacional do dom permite avançar nessa reflexão, na medida em que apreende os antigos conhecimentos como complexos sistemas simbólicos e contribui, assim, para libertar o pensamento crítico moderno dos reducionismos teóricos impostos pela abordagem utilitarista. Além disso, atualizando a dimensão simbólica dos "outros conhecimentos", Mauss se liberta do positivismo cognitivista - baseado no pensamento classificatório - para valorizar as dimensões

\footnotetext{
${ }^{6}$ Com o pensamento decolonial, são as noções de centro e periferia que podem finalmente ser desconstruídas. O pensamento decolonial é, na verdade, uma vasta reação teórica que tem suas origens tanto no centro quanto nas margens do sistema mundial, uma vez que os mecanismos de dominação do capitalismo moderno também ajudaram a colonizar a vida dos países do centro, e não apenas da periferia do sistema mundial.

${ }^{7}$ A crítica pós-colonial, questionando as relações desiguais entre centro e periferia, permitiu a expansão da crítica teórica aos campos de conhecimento e práticas situados na periferia. Com a crítica decolonial, são os próprios conceitos de centro e periferia que tendem a ser desconstruídos, a fim de facilitar a multiplicação de pontos de vista e entendimentos do sistema-mundo.

${ }^{8} \mathrm{~A}$ expansão da compreensão das relações entre o eurocentrismo e alter-centrismo gera pelo menos três tipos de programas de investigação, diz Sérgio Costa: 1) o programa empático que denuncia a teoria para propor um conhecimento "beyond theory"; 2) o programa intermediário que visa mostrar a interdependência estrutural entre a ciência e dominação colonial; 3) o programa moderado que defende a tese de que as narrativas nacionais foram importantes para pensar a organização da modernidade europeia (Costa, 2010).
} 
moral e estética da vida social, as quais são decisivas para o pensamento simbólico. Como bens simbólicos, os dons podem ter um valor moral (a lealdade), mas também um valor estético (um gesto de boas-vindas, um abraço, uma celebração ritual ou um festival religioso...). Este duplo registro revela a riqueza do dom como dispositivo de desconstrução das hierarquias ocidentais de dominação moral e estética. Entendemos, assim, que o Ensaio não é apenas um estudo moral do ocidentalismo, próprio à escola francesa de sociologia, mas também um estudo estético que pareceu a seu autor como tal, quando ele assumiu a vastidão das consequências teóricas produzidas pelo reconhecimento do símbolo nas práticas sociais diversas (Tarot, 1999; Caillé, 2000).

\section{As duas leituras possíveis de Ensaio sobre o dom}

Podemos fazer duas leituras complementares do Ensaio: a primeira, moral, ajuda a desmistificar a ideologia utilitarista do ocidentalismo e a perversão da dominação colonial; a segunda, estética, permite entender a modernidade como um processo de hibridação (hybridization encounter), no qual a ciência racionalista deve, necessariamente, interagir com o pensamento simbólico que se desdobra nas atividades artísticas e literárias. Note-se, aqui, que esta abertura para o pensamento simbólico é mais um argumento contra o reducionismo científico da Europa e suas ex-colônias. São evidentes, de fato, em ambas as interpretações, os esforços de ruptura de Mauss com o pensamento simplista do economismo utilitarista.

\section{Primeira Leitura: um discurso explicitamente antiutilitarista}

Há, em primeiro lugar, no Ensaio, um discurso explicitamente antiutilitarista e crítico dos fundamentos morais da modernização ociden- 
tal - discurso de incluir o elemento não europeu ao lado do elemento europeu. Para Mauss, a filosofia utilitarista que fundamenta o capitalismo reduz a complexidade e a diversidade das ações humanas em sociedade a uma motivação: a de que o ser humano é essencialmente egoísta e calculador. Esta leitura, note-se, desconsidera que a palavra interesse é recente e pertence ao vocabulário técnico financeiro (o interesse latino dos livros de contabilidade). Após esta primeira fase de desconstrução, Mauss retorna a morais mais antigas, particularmente a epicuriana (1999, p. 271). Segundo ele, a diversidade de fatos morais e materiais, por um lado, permite compreender que, nas sociedades tradicionais - europeias e não europeias -, a economia do útil é apenas um elemento de um conjunto bem mais vasto de fenômenos sociais; e, por outro lado, leva necessariamente a pensar a sociedade - tradicional ou contemporânea - como um fato social total ${ }^{9}$. Este ponto crítico teórico deu origem a importantes movimentos culturais e sociais contemporâneos, ocidentais e não ocidentais, como a economia solidária, a democracia participativa, as religiões plurais, o cuidado pessoal entre outros. Finalmente, note-se que a dimensão crítica baseada na moral é a mais conhecida do Ensaio sobre o dom.

\section{Segunda Leitura: uma abordagem estética}

No entanto, é possível fazer uma segunda leitura - rara - do livro de Mauss, que é ao mesmo tempo antiutilitarista e decolonial. Esta dá menos ênfase ao aspecto moral das práticas sociais do que ao aspecto estético, porque Mauss havia compreendido toda a importância devida

\footnotetext{
${ }^{9}$ Nossa demonstração se apoia principalmente na seguinte reflexão: O que eles compartilham não são exclusivamente bens e riquezas, móveis e imóveis, coisas economicamente úteis. São, acima de tudo, cortesias, festas, ritos, serviços militares, mulheres, crianças, danças, festivais, feiras onde o mercado é apenas um momento e a circulação de riquezas é apenas um dos termos de um contrato muito mais amplo e muito mais permanente (Mauss, 1999, p. 151).
} 
aos elementos rituais, trágicos e artísticos deste fato social total que é a sociedade humana. Aqui, a teoria do fato social total renova a teoria crítica, no sentido de trazer um novo olhar, mais compreensivo e não apenas cognitivo, sobre as diferentes formas assumidas pelas práticas sociais no mundo. Suas descrições do potlatch, por exemplo, refletem a importância desses ritos, casamentos, iniciações, sessões xamânicas:

E tudo, clãs, casamentos, iniciações, sessões de xamanismo e de adoração aos deuses, totens ou ancestrais individuais ou coletivos do clã, tudo se mistura em um emaranhado inextricável de ritos, benefícios jurídicos e econômicos, estabelecimento de posições políticas na sociedade dos homens, na tribo e nas confederações de tribos e até internacionalmente (Mauss, 1999, p. 192).

Por isso afirmamos que, apenas considerando a dupla dimensão crítica, moral e estética, pode-se compreender plenamente o que Mauss diz sobre a ação social: é um fato com um valor ao mesmo tempo material e simbólico.

Tal salto teórico permitiu ao sociólogo elaborar, de dentro da modernidade europeia, os fundamentos teóricos de um pensamento decolonial que será sistematizado posteriormente por pensadores maussianos ${ }^{10}$. Esse duplo registro da teoria do fato social total - moral e estético - contribuiu, de fato, para a reorganização do pensamento classificatório - tão importante para a tradição da escola francesa de sociologia -, libertando o pensamento simbólico e criativo que legitima tanto a crítica antiutilitarista (ex-

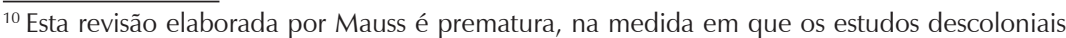
aparecem apenas com a "virada lingüística" de 1980, que reabilita a prática social da vida cotidiana e até mesmo the atribui uma posição central (Dosse, 1999, p. 12). Em outras palavras, o sentido da ação social não pode ser entendido apenas a partir de uma percepção científica e cognitiva do mundo. É necessário repensar a relação entre racionalidade instrumental e racionalidade expressiva.
} 
plícita) quanto a decolonial (implícita) ${ }^{11}$. Isso nos ajuda a compreender o que levou Mauss, estrategicamente, a começar seu ensaio com uma longa visita a textos antigos e não-ocidentais sobre o dom, antes de desenvolver uma crítica estritamente sociológica do utilitarismo ocidental. Esta leitura da estrutura do Ensaio revela a crítica decolonial oculta da obra de Mauss.

\section{$5 \mathrm{O}$ dom como um valor universal}

Continuemos com estes esclarecimentos. Nos três primeiros capítulos do Ensaio sobre o dom, Mauss, graças à sua erudição e seu domínio de diversas línguas, empreende uma viagem ao redor do mundo pré- e não ocidental. Como ele procura demonstrar, antes daquilo a que chamamos lógica utilitarista mercantil, existe outra lógica, antiutilitarista, chamada de dom. Esta proporciona à ação social não apenas uma resposta para os problemas utilitários (detectada pelos próprios filósofos utilitaristas), mas também uma dimensão expressiva (onírica, mágica, sentimental, ritualizada) à origem da complexidade e variedade da existência humana - esta última ideia, intimamente relacionada às críticas decoloniais contemporâneas. Para apoiar seu argumento, Mauss recorre a uma ampla gama de estudos não europeus. Isso Ihe permite mostrar que o sistema do dom, sob a forma do ciclo de dar-receber-retornar, existia antes do surgimento do mercado e do Estado e continua a existir, apesar da ideologia utilitarista dominante que busca, ao contrário, estigmatizar o dom como se fosse incapaz de responder as "evidências" do egoísmo humano.

\footnotetext{
${ }^{11} \mathrm{O}$ pensamento classificatório da escola francesa de sociologia, que se expressa nos esforços de Durkheim e Mauss de explicarem como uma totalidade diversos fatos sociais ligados ao trabalho, à religião e magia. Este pensamento classificatório da escola francesa se inspira originariamente nos sistemas categoriais que Aristóteles considerava central para o pensamento humano conhecer a realidade.
} 
O pensador francês sistematiza a dimensão moral do seu pensamento, que se presta a crítica decolonial, utilizando dois tipos de documentos: a) poemas, textos tradicionais e descrições etnográficas sobre as modalidades de troca de presentes, serviços e hospitalidade, especialmente as modalidades de práticas agonísticas em festivais e rituais; b) descrições diversas sobre os sistemas de lei e costumes tradicionais que garantem a obrigação ritual do dom entre povos não europeus.

Os primeiros documentos são analisados na introdução e nos capítulos I (Os dons trocados e a obrigação de retorná-los (Polinésia)) e II (Extensão desse sistema [liberalidade, honra, dinheiro]). O Ensaio se inicia com um antigo poema escandinavo, o Havamal, usado por Mauss para criar a atmosfera em que vai mergulhar o leitor. Ele busca destacar o sistema do dom particularmente em alguns povos arcaicos (antigos habitantes da Escandinávia) e não europeus (indígenas do nordeste da América do Norte, nativos das ilhas Trobriand na Nova Zelândia, esquimós do Pólo Norte, pigmeus da África...). Ao longo desta seção, Mauss explica que o sistema do dom entre as sociedades tradicionais não europeias baseava-se principalmente na rivalidade ou competição entre pessoas morais, implicando toda a energia social coletiva. Entre os vários tipos de benefícios identificados, o potlatch é aquele em que Mauss mais se concentra. Ele também aborda situações nas quais, mesmo que não haja potlatch - por exemplo, nos rituais de nascimento de meninos ou nos casamentos em Samoa, Polinésia Francesa -, há ainda um sistema de obrigações mútuas. O dom se manifesta sempre por meio de regras de honra, prestígio e de redistribuição de serviços e presentes que obrigam mutuamente todos os protagonistas. A não redistribuição dos presentes significa a perda do mana, ou seja, da autoridade de cada um no seio da comunidade. Como explica Mauss: Recusar doar, deixar de convidar, como recusar aceitar, equivalem a declarar uma guerra; é recusar a aliança e a comunhão (Mauss, 1999, p. 162-163). 
Embora tenha o potlatch como o sistema central de uma série de sociedades tradicionais não europeias (na Austrália ou nos Estados Unidos), Mauss reconhece a existência de outros tipos de dom que não se baseiam em rivalidade, mas em devoção ou amizade. Tal como o dom da caridade entre os membros da tribo Haoussa do Sudão, onde uma crença popular diz que a febre se espalha quando o trigo está maduro e a única maneira de parar a doença é fornecendo trigo para os pobres ( $p$. 169). Entre os Pigmeus, encontra-se o dom da hospitalidade (festivais e feiras, obrigatórios e voluntários) cuja intenção é principalmente moral, sendo o objetivo criar um sentimento de amizade entre duas pessoas: Ninguém está livre para recusar um presente oferecido (p. 173). Entre os povos das ilhas Trobriand, na Nova Caledônia, Mauss explora a relação entre o dom e a kula ${ }^{12}$, um sistema de comércio intertribal envolvendo tribos de diferentes ilhas da região. Em algumas épocas do ano, membros de uma tribo atravessam o mar para oferecer joias, alimentos etc. aos membros de outras tribos. Em outro momento, a kula é seguida por um movimento no sentido oposto (p. 175): A kula, sua forma essencial, é por si só um momento, o mais solene, de um extenso sistema de benefícios e contra-benefícios que, na verdade, parece abranger toda a vida econômica e civil dos Trobriand (p. 185).

Outros documentos usados por Mauss para estabelecer sua crítica decolonial são descrições de vários regimes jurídicos e costumes presentes em todas as sociedades humanas pré-modernas. No capítulo III (Sobrevivências desses princípios nos direitos antigos e nas economias antigas), ele descreve vários sistemas jurídicos - o direito romano, o direito hindu clássico, o direito germânico, o direito celta, o direito chinês, entre outros - nos quais ele revela resquícios dos princípios do dom, o que é

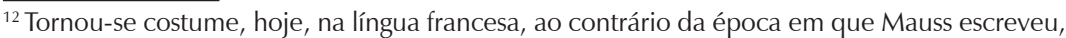
usar o vernáculo kula no feminino.
} 
interessante para a compreensão da força do dom em instituições sociais. Mauss mostra, assim, que o dom não existe apenas nas sociedades de transmissão oral, mas também em sociedades complexas, não europeias ou europeias, de direito escrito.

Com estes pensamentos ele abre suas vastas conclusões sobre a atualidade do dom. A segunda parte do Ensaio (o quarto e último capítulo, intitulado "Conclusão") aprofunda a primeira parte, demonstrando que, por trás das trocas econômicas, há sempre uma trama simbólica que organiza os lugares, cria expectativas e pode produzir a guerra e a paz, a amizade e a inimizade ${ }^{13}$. Mauss abre, assim, uma nova janela de compreensão sugerindo que a dignidade humana é o fruto da condição moral partilhada pelos indivíduos e o sentimento de transcendência é aquele de sua coabitação ritual e extática ${ }^{14}$. Pode-se concluir - ainda que a importância capital da primeira parte do livro para o desenvolvimento da segunda parte seja negligenciada na maior parte do tempo - que Mauss passa, aqui, de uma crítica decolonial a uma crítica à economia de mercado ocidental, uma crítica propriamente antiutilitarista.

\section{A ideia de totalidade social}

Como acabamos de ver, o Ensaio sobre o dom não se limita a uma obra de interesse etnográfico, na qual Mauss simplesmente descreve os costumes e práticas de sociedades não europeias passadas. Nossa leitura, estética e decolonial, revela que o texto contém, implicitamente, uma re-

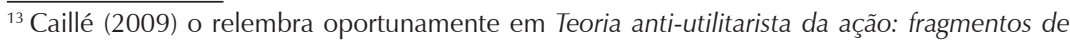
uma sociologia geral.

${ }^{14}$ Essas oposições binárias complexas - vida e morte, guerra e paz, interesse e gratuidade, liberdade e obrigação - emprestadas de Marcel Mauss, são a base da teoria anti-utilitarista da ação acima lembrada, de Alain Caille.
} 
visão teórica da crítica moral e da valorização das motivações da vida em comum. Mais especificamente, nos interstícios da crítica moral, aparece uma segunda crítica, estética, que exalta os aspectos lúdicos, dramáticos, trágicos e artísticos da prática social e das instituições sociais. Temos, assim, uma dupla crítica, moral e estética, central para compreender o projeto de Mauss: mostrar que a vida em comum é, sobretudo, um fato social total, uma totalidade, implicando todos os aspectos, subjetivos e objetivos, do ser humano, e que deve ser reconhecida em sua complexidade, sua singularidade e sua diversidade.

Em Mauss, de fato, a ideia de totalidade da sociedade (os fatos que estudamos são todos fatos sociais totais ou gerais [...] (Mauss, 1999, p. 274)) excede e se opõe ao pensamento cognitivista que ele considera abstrato e de pouca utilidade para observar a realidade concreta. Isso implica considerar que todos os fenômenos são ao mesmo tempo jurídicos, econômicos, religiosos e, até mesmo, estéticos e morfológicos:

Todos os pesquisadores deveriam observar o comportamento dos seres totais e não divididos em faculdades. [...] $O$ estudo do concreto, que é o estudo do completo, é possível e mais cativante e mais explicativo ainda na sociologia. $O$ princípio e o fim da sociologia é perceber o grupo inteiro e seu comportamento inteiro (Mauss, 1999, p. 276).

Embora o Ensaio seja basicamente uma crítica moral do ocidentalismo, Mauss demonstra que a definição estética do dom é central para a crítica geral e para a renovação da sociologia. Nessa perspectiva, ele afirma que todas as instituições têm um lado estético, mas declara não ter tido tempo para se aprofundar e insiste para que este aspecto das coisas seja assinalado:

[...] as danças que executamos alternativamente, os cantos e desfiles de todos os tipos, as representações dramáticas que fazemos de campo a campo e de parceiro a parceiro; os objetos de todos os tipos que fabricamos, usamos, ornamos, 
polimos, coletamos e transmitimos com amor, tudo o que nós recebemos com alegria e presenteamos com sucesso [...] é tudo por causa da emoção estética e não apenas das emoções de ordem moral ou de interesse (Mauss, 1999, p. 276).

E ele conclui seu ensaio sugerindo que a organização do pensamento sociológico deve considerar a articulação de toda a sociedade com a arte da política:

Nós vemos também como este estudo empírico pode levar não só a uma ciência da moral, uma ciência social parcial, mas também a conclusões morais, ou melhor - para retomar a velha palavra - de "civilidade", de "cidadania" como se diz agora. Estudos deste tipo tornam possível perceber, medir, equilibrar os diversos móbiles estéticos, morais, religiosos, econômicos, os diversos fatores materiais e demográficos cujo conjunto constitui a vida em comum e cuja direção consciente é a arte suprema, a Política, no sentido socrático da palavra (Mauss,1999, p. 279).

O interesse deste parágrafo final é a referência explícita à política como pré-requisito para a compreensão das diversas motivações da ação social, passadas ou presentes. Na verdade, uma leitura detalhada do Ensaio nos leva a entender que a aliança é um fenômeno que envolve diversas motivações morais e expressões estéticas e que o pensamento classificatório deve ampliar a compreensão cognitiva, incluindo também o pensamento simbólico. Nada é dado a priori sobre o plano simbólico, como erradamente afirmou Claude Lévi-Strauss, nem sobre o plano das forças econômicas, como equivocadamente pensam os economistas. Ao contrário, tudo se define pela capacidade das pessoas coletivas e individuais de sair de si, de doar livremente e obrigatoriamente. Não há risco de erro (Mauss, 1999, p. 265). Vale lembrar que o texto termina por uma vontade de abrir o pensamento simbólico em direção ao pensamento político, vontade que se encontra igualmente hoje entre os pensadores da crítica decolonial. 


\section{Em conclusão: o "fato social total" como teoria decolonial}

Este alargamento do espectro crítico da obra de Mauss permite destacar o valor heurístico da teoria do fato social total e do dom e confere certa coerência à crítica decolonial, ao articular duas escolas de pensamento: a do "centro" que se provincializa, segundo a análise de Chakrabarty (2008) apresentada na introdução, e a da "periferia" que se espalha, de acordo com outro autor importante, o peruano Aníbal Quijano (2005). Isso também abre oportunidades significativas para o diálogo entre os diversos campos de produção da crítica sociológica, ao Norte e ao Sul, especialmente a crítica latino-americana que promove uma revisão epistêmica e epistemológica significativa das margens ${ }^{15}$.

Concluímos, portanto, propondo dois elementos de discussão. O primeiro, para dizer que a crítica antiutilitarista baseada no reconhecimento do valor das práticas na obra de Mauss é também uma crítica decolonial não explícita. Para desenvolver sua crítica ao reducionismo mercantil, o sociólogo vai se interessar de perto pelos costumes e rituais de diversas sociedades não europeias. E é a partir dessas margens que Mauss percebe o eurocentrismo como um projeto histórico e cultural particular, que se revela plenamente sua crítica antiutilitarista, embora ele não tenha, claro, usado os termos mais contemporâneos da crítica teórica. As releituras mais recentes do Ensaio pelo Movimento Antiutilitarista nas Ciências

\footnotetext{
${ }^{15} \mathrm{Na}$ América Latina, já assistimos, há várias décadas, uma importante crítica ao imperialismo e aos aspectos econômicos e políticos das trocas entre o centro e as margens do capitalismo global. Essa crítica aparece, por exemplo, no que chamamos de pensamento pós-colonial propriamente dito: o que é a base do pensamento estruturalista da Comissão Econômica para a América Latina (CEPAL) e a Teoria da Dependência. Essas teorias têm sido fundamentais para conceber a região não como um conglomerado de Estados nacionais dependentes, mas como um sistema dotado de particularidades históricas, políticas, econômicas, culturais e linguísticas (Morana; Dussel; Jauregui, 2008). Mais recentemente, vimos o surgimento de pensamentos decoloniais que visam desconstruir a relação imaginária centro-periferia e promover o "bem viver" dos povos indígenas Aymara da Bolívia e do Equador.
} 
Sociais (MAUSS), baseado na França, seguem neste sentido, clarificando a relação estreita entre crítica à filosofia do interesse comercial e crítica à colonização do poder e do conhecimento. Na última reunião da Associação Latino-Americana de Sociologia (ALAS) em Recife, em 2011, Caillé concluiu sua apresentação sobre o estado atual da sociologia observando que, contrariamente à tradição econômica que estabelece a utilidade como valor econômico fundamental de bens e mercadorias, a sociologia - e também a antropologia, a filosofia e a história - repousa sobre uma hipótese muito diferente, que encontra sua base no Ensaio sobre o dom:

O que os grupos sociais em conflito, mulheres, subalternos, antigas colônias, prestadores de cuidados etc. querem ver reconhecido é o valor dos dons que fizeram (ou que lhes foram tirados) (Caillé, 2010, p. 54).

Gostaríamos, também, de salientar que, se a crítica decolonial se revela com toda sua força discursiva nas sociedades do Sul, seu interesse para a teoria social vai muito além. Quanto mais se desenvolvem as pesquisas sobre o fenômeno colonial, mais constatamos de fato que o imperialismo ocidental também se organizou a partir da colonização do interior da própria Europa. A obra de Franz Fanon (1975) sobre o preconceito étnico na França, por exemplo, mostra que, por trás das desigualdades republicanas das grandes democracias ocidentais, existem sistemas hierárquicos que contribuíram, durante vários séculos, para incluir ou excluir, com base em linhas étnicas - uma análise que pode ser estendida às dominações que se fazem com base em critérios de idade, sexo, religião etc. O que o Ensaio sobre o Dom não mostra é que a disseminação da cultura ocidental, ao longo de todo o seu processo de modernização, não poderia ser feita sem humilhação ou violência contra mulheres, crianças e estrangeiros, tanto no "centro" como na "periferia". Uma tal crítica já está em andamento em todos aqueles que procuram refletir sobre a "subalter- 
nidade" dos povos do Sul ou das classes sociais ao Norte, o que amplifica a desconstrução crítica da colonização planetária.

Assim, acreditamos que a crítica ao espírito europeu colonial (Cairo; Grosfoguel, 2010) é consistente com uma reestruturação simbólica da Europa: a que reconhece que o utilitarismo econômico participou da destruição da ideia da totalidade social dentro deste momento sócio-histórico chamado Europa. A provincialização da Europa pode ser uma chance para que ela se liberte do peso de seu universalismo racionalista eurocêntrico ${ }^{16}$.

Paulo Henrique Martins - Doutor em Sociologia pela Université de Paris I (Panthéon-Sorbonne) com pós-doutorado na Universidade de Paris-Nanterre. Professor Titular do Departamento de Sociologia e Coordenador do NUCEM (Núcleo de Cidadania e Processos de Mudança) da Universidade Federal de Pernambuco. Presidente da ALAS (Associação Latino-Americana de Sociologia); Vice-Presidente da Associação MAUSS (Mouvement Anti-Utilitariste dans les Sciences Sociales). $\sum$ pahem@terra.com.br

\section{Referências}

1. BOATO, M. Múltiples Europas y la mística de la unidad. In: CAIRO, H. E, GROSFOGUEL, R. Descolonizar la modernidad, descolonizar Europa; un diálogo Europa-América. Madrid: IEPALA, 2010.

2. CAILLÉ, A. O estado atual da sociologia. Algumas observações face ao próximo congresso ALAS, Estudos de Sociologia: Revista do Programa de Pós-Graduação em Sociologia da UFPE, v. 16, n. 2, p. 45-56, 2010.

3. CAILLÉ, A. Théorie anti-utilitariste de l'action: fragments d'une sociologie générale. Paris: La Découverte, 2009.

\footnotetext{
${ }^{16}$ Recordemos a mitologia grega. Na véspera de ser raptada por Zeus, a princesa Europa teve um pesadelo em que duas mulheres se apresentam para reivindicar seus direitos. Uma, Ásia, se dizia sua mãe; a outra, uma desconhecida ("a terra da margem oposta"), América, argumentava que Europa Ihe foi dada por Zeus. Se buscarmos atualizar este mito, veremos que a modernidade europeia foi o resultado de uma relação muito intensa, pode-se mesmo falar de uma relação simbiótica com a Ásia e a América.
} 
4. CAILLÉ, A. Anthropologie du Don. Le tiers paradigme. Petrópolis: Editora Vozes, 2000.

5. CAIRO, H. E.; GROSFOGUEL, R. Descolonizar la modernidad, descolonizar Europa; un diálogo Europa-América. Madrid: IEPALA, 2010.

6. CAIRO H. E., BRINGEL, B. Articulaciones del Sur Global: afinidad cultural, internacionalismo solidario e iberoaméricaen la globalización contrahegemónica. In: CAIRO H. E, GROSFOGUEL R. Descolonizar la modernidad, descolonizar Europa; un diálogo Europa-América. Madrid: IEPALA, 2010.

7. CHAKRABARTY, D. In defense of provincializing Europe: a response to Carole Dietze, History and Theory, v. 47, n.1, p. 85-96, 2008.

8. CHAKRABARTY, D.; MAJUMDAR, R.; SARTORI, A. From the Colonial to the Postcolonial: India and Pakistan in Transition, Oxford: Oxford University Press, 2007.

9. COSTA, S. (Re)encontrando-se nas redes? As ciências humanas e a nova geopolítica do conhecimento, Estudos de Sociologia: Revista do Programa de PósGraduação em Sociologia da UFPE, v. 16, n. 2, p. 25-44, 2010.

10. DOSSE, F. L'Empire du sens: I'humanisation des sciences humaines. Paris :. La Découverte, 1997.

11. FANON, F. Pele negra, máscaras brancas. Porto: Paisagem, 1975.

12. FOUCAULT, M. Naissance de la biopolitique. Paris : Seuil, 2004.

13. KRAMSCH, O. Dans le ballon rouge? Entre el proyecto modernidad/colonialidad latinoamericano y la Europa fronteriza realmente existente. In: CAIRO, $\mathrm{H}$. E.; GROSFOGUEL, R. Descolonizar la modernidad, descolonizar Europa; un diálogo Europa-América. Madrid: IEPALA, 2010.

14. MARTINS, P. H. La decolonialidad de América Latina y la heterotopia de una comunidad de destino solidaria. Buenos Aires: Ediciones Ciccus, 2012.

15. MARTINS, P. H. La crítica anti-utilitarista en el Norte y su importancia para el avance del pensamiento poscolonial en las sociedades del Sur, Política \& Sociedade: Revista de Sociologia Política, v. 10, n. 18, p. 111-132, 2011.

16. MARTINS, P. H. Sur y Norte como experiencias epistemológicas necesárias a la decolonialidad, Estudos de Sociología: Decolonialidade e giros epistemológicos, Recife, v. 16, n. 2, p. 73-96, 2010.

17. MAUSS, M. Sociologie et anthropologie. Paris: PUF, 1999 (1924).

18. MORAÑA, M.; DUSSEL, E.; JÁUREGUI, A. Coloniality at large: Latin America and the Poscolonial Debate. Duhram et London: Duke University Press, 2008. 
19. NIETZSCHE, F. Obras incompletas. São Paulo: Editora Nova Cultural, 1999. 20. QUIJANO, A. Colonialidad del poder, eurocentrismo y América Latina. In: LANDER E. (dir.). La colonialidad del saber: Eurocentrismo y ciencias sociales. Perspectivas Latinoamericanas. Buenos Aires: Clasco, 2003. p. 201-245.

21. TAROT, C. De Durkheim à Mauss, I'invention du symbolisme. Sociologie et sciences des religions. Paris: La Découverte/MAUSS, 1999.

22. TAYLOR, C. As fontes do self. São Paulo: Edições Loyola, 1997.

23. WALLERSTEIN, I. Impensar a Ciência Social: Os limites dos paradigmas do século XIX. São Paulo: Ideias Letras, 2006.

Recebido em: 17/02/2014

Aceite final: 10/04/2014 